\title{
Kinetic studies of the reaction of hydroxyl radicals with trichloroethylene and tetrachloroethylene
}

\author{
LeAnn B. Tichenor ${ }^{\text {a }}$, Abdulaziz El-Sinawi a, Takahiro Yamada ${ }^{\text {a }}$, \\ Philip H. Taylor ${ }^{\mathrm{a}, *}$, Jingping Peng ${ }^{\mathrm{b}}$, Xiaohua $\mathrm{Hu}^{\mathrm{b}}$, Paul Marshall ${ }^{\mathrm{b}}$

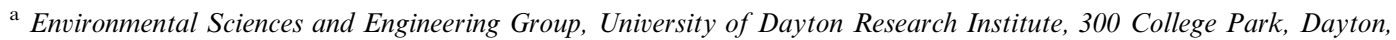 \\ OH 43469-0132, USA \\ ${ }^{\mathrm{b}}$ Department of Chemistry, University of North Texas, P.O. Box 305070, Denton, TX 76203-5070, USA
}

\begin{abstract}
Rate coefficients are reported for the gas-phase reaction of the hydroxyl radical $(\mathrm{OH})$ with $\mathrm{C}_{2} \mathrm{HCl}_{3}\left(k_{1}\right)$ and $\mathrm{C}_{2} \mathrm{Cl}_{4}$ $\left(k_{2}\right)$ over an extended temperature range at $740 \pm 10$ Torr in a He bath gas. These absolute rate measurements were accomplished using a laser photolysis/laser-induced fluorescence (LP/LIF) technique under slow flow conditions. The simple Arrhenius equation adequately describes the low temperature data for $k_{1}(<650 \mathrm{~K})$ and the entire data set for $k_{2}$ and is given by (in units of $\mathrm{cm}^{3}$ molecule $\mathrm{e}^{-1} \mathrm{~s}^{-1}$ ):

$$
\begin{aligned}
& k_{1}(291-650 \mathrm{~K})=(9.73 \pm 1.15) \times 10^{-13} \exp (158.7 \pm 44.0) / T, \\
& k_{2}(293-720 \mathrm{~K})=(1.53 \pm 0.14) \times 10^{-12} \exp (-688.2 \pm 67.5) / T .
\end{aligned}
$$

Error limits are $2 \sigma$ values. The room temperature values for $k_{1}$ and $k_{2}$ are within $\pm 2 \sigma$ of previous data using different techniques. The Arrhenius activation energies for $k_{1}$ and $k_{2}$ are a factor of 2-3 lower than previously reported values. The experimental measurements for both $k_{1}$ and $k_{2}$ in conjunction with transition state and variation transition state theory calculations infer an $\mathrm{OH}$ addition mechanism. The lack of a measurable kinetic isotope effect for $k_{1}$ is consistent with this mechanism. Insight into the subsequent reactions of the chemically activated intermediate are presented in the form of potential energy diagrams derived from ab initio calculations. (c) 2001 Elsevier Science Ltd. All rights reserved.
\end{abstract}

Keywords: Chlorinated hydrocarbons; Hydroxyl; Kinetics; Oxidation, reaction mechanisms

\section{Introduction}

Past and present manufacturing and disposal practices have resulted in the release of trichloroethylene $\left(\mathrm{C}_{2} \mathrm{HCl}_{3}\right)$ and tetrachloroethylene $\left(\mathrm{C}_{2} \mathrm{Cl}_{4}\right)$ into the atmosphere at significant rates. The annual amount of $\mathrm{C}_{2} \mathrm{HCl}_{3}$ and $\mathrm{C}_{2} \mathrm{Cl}_{4}$ emitted in the US alone was estimated to be $\sim 2.5 \times 10^{5}$ and $\sim 1 \times 10^{5}$ metric tons, respectively (Gilbert et al., 1980; Thomas et al., 1981).

\footnotetext{
* Corresponding author. Fax: +1-937-229-2503.

E-mail address: taylorph@udri.udayton.edu (P.H. Taylor).
}

The dominant atmospheric loss reaction is reaction with $\mathrm{OH}$ radicals since chloroethenes do not absorb radiation at wavelengths $>300 \mathrm{~nm}$, nor do they react significantly with $\mathrm{O}_{3}$ or $\mathrm{NO}_{3}$ in the gas phase (Atkinson et al., 1987; Atkinson, 1989). Rate constants at low temperatures $(220-430 \mathrm{~K})$ have been reported previously (Howard, 1976; Chang and Kaufman, 1977; Davis et al., 1977; Kirchner et al., 1990). The reaction mechanism is presumed to be addition to the $\pi$ electrons associated with the $\mathrm{C}=\mathrm{C}$ double bond. Kirchner et al. (1990), measured reaction products from $\mathrm{OH}$ reactions with $\mathrm{C}_{2} \mathrm{HCl}_{3}$ and $\mathrm{C}_{2} \mathrm{Cl}_{4}$ at low temperatures $(300-450 \mathrm{~K})$ using electron impact mass spectrometry. The observed 
product distributions were complex with the dominant mass spectra signals interpreted in terms of a reaction mechanism involving $\mathrm{OH}$ addition and subsequent $\mathrm{Cl}$ elimination. The relative importance of adduct stabilization versus $\mathrm{Cl}$ elimination has not been determined.

High temperature incineration is considered to be the best available technology for the safe disposal of these toxic compounds. The fastest process contributing to the destruction of halogenated hydrocarbons is the reaction with $\mathrm{OH}$ radicals (Fairchild et al., 1982; Warnatz et al., 1982). Given the lack of available data above $400 \mathrm{~K}$, knowledge of the reaction rate constants and reaction mechanisms over an extended temperature range is essential to accurately predict the combustion behavior of these compounds.

We present atmospheric pressure, absolute rate coefficients for the reaction of $\mathrm{OH}$ with $\mathrm{C}_{2} \mathrm{HCl}_{3}$ (and $\left.\mathrm{C}_{2} \mathrm{DCl}_{3}\right)\left(k_{1}\right)$ and $\mathrm{C}_{2} \mathrm{Cl}_{4}\left(k_{2}\right)$ over an extended temperature range:

$$
\begin{aligned}
& \mathrm{C}_{2} \mathrm{HCl}_{3}+\bullet \mathrm{OH} \rightarrow \text { products }\left(k_{1}\right) \\
& \mathrm{C}_{2} \mathrm{Cl}_{4}+\bullet \mathrm{OH} \rightarrow \text { products }\left(k_{2}\right)
\end{aligned}
$$

Arrhenius parameters are derived from the data. A comparison of these measurements with prior measurements at lower temperatures and pressures is discussed. Insight into the possible reaction mechanisms is also discussed based on transition state theory and variational transition state theory calculations and ab initio calculations of plausible reaction channels.

\section{Experimental approach and data reduction}

The experimental procedures were similar to those used in previous studies of the reaction of $\mathrm{OH}$ radicals with halogenated hydrocarbons (Fang et al., 1997, 1999). The method used to generate the precursor for the hydroxyl radical varied from previous experimentation. Initial testing of $\mathrm{C}_{2} \mathrm{HCl}_{3}$ and $\mathrm{C}_{2} \mathrm{Cl}_{4}$ was performed using $193 \mathrm{~nm}$ photolysis of $\mathrm{N}_{2} \mathrm{O} / \mathrm{H}_{2} \mathrm{O}$ as the $\mathrm{OH}$ source, as had been done previously. The resulting room-temperature rate measurements exceeded previously reported values by a factor of two $\left(\mathrm{C}_{2} \mathrm{HCl}_{3}\right)$ and $10\left(\mathrm{C}_{2} \mathrm{Cl}_{4}\right)$ (Howard, 1976; Chang and Kaufman, 1977; Davis et al., 1977; Kirchner et al., 1990). Due to the large absorption crosssections of $\mathrm{C}_{2} \mathrm{HCl}_{3}$ and $\mathrm{C}_{2} \mathrm{Cl}_{4} \quad\left(>5 \times 10^{-18} \mathrm{~cm}^{2} /\right.$ molecule) (Zabel, 1974), additional measurements were conducted at low excimer laser fluences $\left(<1 \mathrm{~mJ} \mathrm{~cm}^{-2}\right)$, with no observed reduction in rate coefficients. These results indicated that operation at $193 \mathrm{~nm}$ was unacceptable and necessitated the use of a different $\mathrm{OH}$ generation method. To minimize substrate photolysis, HONO was used as a hydroxyl radical source, which dissociated to $\mathrm{NO}$ and $\mathrm{OH}$ when exposed to near-UV radiation of 351 nm. A XeF excimer laser (Lamba Physik Compex Model
102) was used as the photodissociation source. Initial $[\mathrm{OH}]_{0}$ ranged from $\sim 2$ to $4 \times 10^{11}$ molecules $\mathrm{cm}^{-3}$, and was determined based on the measured excimer fluence $\left(9-18 \mathrm{~mJ} \mathrm{~cm}^{-2}\right)$, the published value of the absorption cross-section for HONO, $2.12 \times 10^{-19} \mathrm{~cm}^{2} /$ molecule at $351 \mathrm{~nm}$ (Demore et al., 1997), a quantum yield of 1.0 (Cox, 1974), and measured values of $\left[\mathrm{NO}_{2}^{-}\right]$taken to represent [HONO] determined using ion chromatography $\left(\sim 5 \times 10^{13}\right.$ molecules $\left.\mathrm{cm}^{-3}\right)$.

Initial substrate concentrations ranged from $\sim 3 \times 10^{13}$ to $1 \times 10^{15}$ molecules $\mathrm{cm}^{-3}$. All experiments were conducted at a total pressure of $740 \pm 10$ Torr. Samples of $\mathrm{C}_{2} \mathrm{HCl}_{3}$ and $\mathrm{C}_{2} \mathrm{Cl}_{4}$ were obtained from Aldrich with $99.9 \%$ purity. Gas chromatography-mass spectrometry (GC/MS) analyses indicated that this purity was met or exceeded.

Initial measurements at or near room temperature required passivation of the injector probe prior to collecting reliable data. Following these measurements, the injection probe was cleaned and treated with boric acid to reduce the reactivity of the surface. Subsequent measurements taken over a three month time period did not show any re-occurring effects of surface adsorption.

The rate of disappearance of the $\mathrm{OH}$ may be presented as:

$-\mathrm{d}[\mathrm{OH}] / \mathrm{d} t=k\left[\mathrm{~A}_{\mathrm{o}}\right][\mathrm{OH}]+k_{\mathrm{d}}[\mathrm{OH}]$

where $k$ is the bimolecular rate constant, $A_{\mathrm{o}}$ the organic concentration, and $k_{\mathrm{d}}$ is the first-order rate for the reaction of $\mathrm{OH}$ with impurities; considers diffusion out of the reaction volume.

This relationship holds in the absence of any secondary reactions that may form or deplete $\mathrm{OH}$. Solution of this equation yields $[\mathrm{OH}]=[\mathrm{OH}]_{\mathrm{o}} \exp \left(-k^{\prime} t\right)$, where $k^{\prime}=k+k_{\mathrm{d}}$. For all experiments, reactive and diffusive $\mathrm{OH}$ radical decay profiles exhibited exponential behavior and were fitted by the following nonlinear expression:

$[\mathrm{OH}]=[\mathrm{OH}]_{\mathrm{o}} \exp \left(-k^{\prime} t\right)+\gamma$,

where $\gamma$ is the constant background signal level and $t$ is the time delay between the laser pulses. As the organic concentration was much greater than the $[\mathrm{OH}]$, pseudo first-order exponential $\mathrm{OH}$ decays were observed and the individual temperature dependent rate constants were determined by $k^{\prime}=k$ [organic $]+k_{\mathrm{d}}$, where the bimolecular rate constant $k$, is the slope of the leastsquares fit of $\mathrm{k}^{\prime}$ versus the [organic]. $\mathrm{OH}$ decays were observed over two to three decay lifetimes over a time interval of $0.3-20.0 \mathrm{~ms}$.

\section{Results}

Absolute rate coefficients for $k_{1}$ and $k_{2}$ are presented in Tables 1 and 2, respectively. Random error limits 
$( \pm 2 \sigma)$ were below $20 \%$ in most cases. When identifying possible side reactions, two reactions of concern are hydroxyl and/or organic reaction with excess $\mathrm{HCl}$ and $\mathrm{H}_{2} \mathrm{O}$. These two compounds were present in the system as carryovers from the HONO reactor. These and other possible side reactions were simulated numerically using reaction rate constants published in the NIST chemical kinetics database (Mallard, 1998). The results of this analysis indicated that side reactions would not impact significantly on the reaction under observation with the input concentrations used. In the absence of reactant impurities, sources of systematic error were then limited to thermally-induced secondary reactions. The possibility of thermally-induced side products was investigated by varying the total gas flow rate. $k_{1}$ and $k_{2}$ was found to be independent of the residence time in the mid to hightemperature regions, implying a lack of thermal reaction of the substrates at elevated temperatures. Above $750 \mathrm{~K}$, an excess of $\mathrm{OH}$ radical generation in the absence of the photolytic laser pulse was observed, and $\mathrm{OH}$ decays were not measurable.

All known absolute rate measurements for $k_{1}$ and $k_{2}$ are summarized in Figs. 1 and 2, respectively. This work

Table 1

Absolute rate coefficients for $k_{1}{ }^{\mathrm{a}}$

\begin{tabular}{ll}
\hline Temp $(\mathrm{K})$ & $10^{12} k_{1}\left(\mathrm{~cm}^{3}\right.$ molecule $\left.^{-1} \mathrm{~s}^{-1}\right)$ \\
\hline 291 & $1.81 \pm 0.26$ \\
292 & $1.89 \pm 0.24$ \\
292 & $1.72 \pm 0.32^{\mathrm{b}}$ \\
293 & $1.70 \pm 0.28$ \\
294 & $1.55 \pm 0.22$ \\
326 & $1.56 \pm 0.14$ \\
330 & $1.50 \pm 0.18$ \\
356 & $1.44 \pm 0.22$ \\
410 & $1.40 \pm 0.20$ \\
417 & $1.41 \pm 0.22$ \\
422 & $1.38 \pm 0.32$ \\
467 & $1.40 \pm 0.10$ \\
500 & $1.37 \pm 0.32$ \\
502 & $1.37 \pm 0.32$ \\
505 & $1.23 \pm 0.18$ \\
508 & $1.37 \pm 0.32$ \\
562 & $1.22 \pm 0.20$ \\
621 & $1.40 \pm 0.22$ \\
650 & $1.28 \pm 0.34$ \\
699 & $1.35 \pm 0.30^{\mathrm{b}}$ \\
709 & $1.67 \pm 0.12$ \\
711 & $2.02 \pm 0.18$ \\
719 & $1.64 \pm 0.26$ \\
720 & $1.68 \pm 0.15$ \\
746 & $2.00 \pm 0.54$ \\
750 & $1.63 \pm 0.26$ \\
752 & $1.94 \pm 0.28$ \\
\hline
\end{tabular}

${ }^{a}$ Errors represent $\pm 2 \sigma$ and do not include the $5-10 \%$ uncertainty estimated for possible systematic errors.

${ }^{\mathrm{b}} \mathrm{C}_{2} \mathrm{DCl}_{3}$.
Table 2

Absolute rate coefficients for $k_{2}{ }^{\mathrm{a}}$

\begin{tabular}{ll}
\hline Temp $(\mathrm{K})$ & $10^{13} k_{2}\left(\mathrm{~cm}^{3}\right.$ molecule $\left.{ }^{-1} \mathrm{~s}^{-1}\right)$ \\
\hline 293 & $1.52 \pm 0.17$ \\
350 & $2.13 \pm 0.13$ \\
400 & $2.85 \pm 0.21$ \\
440 & $3.12 \pm 0.12$ \\
500 & $4.06 \pm 0.04$ \\
550 & $4.61 \pm 0.41$ \\
640 & $5.50 \pm 0.24$ \\
700 & $5.63 \pm 0.18$ \\
720 & $5.88 \pm 0.55$ \\
\hline
\end{tabular}

${ }^{a}$ Errors represent $\pm 2 \sigma$ and do not include the $5-10 \%$ uncertainty estimated for possible systematic errors.

extends experimental measurement beyond the limit of $\sim 450 \mathrm{~K}$ reported previously. A variety of techniques were used in collecting these data. Examination of Figs. 1 and 2 shows agreement at room temperature, within combined experimental uncertainties, between our work and that reported previously (Howard, 1976; Chang and Kaufman, 1977; Davis et al., 1977; Kirchner et al., 1990).

Rate measurements for $k_{1}$ exhibited complex behavior with a negative temperature dependence at temperatures below $650 \mathrm{~K}$ and a positive temperature dependence at higher temperatures. The simple Arrhenius equation adequately describes the low temperature data for $k_{1}(<650 \mathrm{~K})$ and the entire data set for $k_{2}$ and is given by (in units of $\mathrm{cm}^{3}$ molecule $\mathrm{e}^{-1} \mathrm{~s}^{-1}$ ):

$$
\begin{aligned}
k_{1}(291-650 \mathrm{~K})= & (9.73 \pm 1.15) \times 10^{-13} \\
& \times \exp (158.7 \pm 44.0) / T \\
k_{2}(293-720 \mathrm{~K})= & (1.53 \pm 0.14) \times 10^{-12} \\
& \times \exp (-688.2 \pm 67.5) / T .
\end{aligned}
$$

Error limits are $2 \sigma$ values. Additional measurements for $k_{1}$ at higher temperatures $(>750 \mathrm{~K})$ are required to provide a statistically valid Arrhenius expression for this temperature regime. Although our room temperature data for both $k_{1}$ and $k_{2}$ are in agreement with previous studies, the measured temperature dependence differs considerably with previous studies. For $\mathrm{C}_{2} \mathrm{HCl}_{3}$, the Arrhenius activation energy derived from our lower temperature data $(-315 \mathrm{cal} / \mathrm{mol})$ is considerably lower than the values of -885 and $-478 \mathrm{cal} / \mathrm{mol}$ reported by Chang and Kaufman (1977) and Kirchner et al. (1990), respectively, over more limited temperature ranges. Surface adsorption effects, a well-known source of systematic error in discharge flow type kinetic measurements, may be the cause of the enhanced reactivity and larger negative temperature dependence of $\mathrm{C}_{2} \mathrm{HCl}_{3}$ at sub-ambient temperatures in the previous measurements (see Fig. 1). For $\mathrm{C}_{2} \mathrm{Cl}_{4}$, the temperature dependence of our measurements from 293 to $720 \mathrm{~K}$ yields an Arrhenius activation energy of $\sim 1.4 \mathrm{kcal} / \mathrm{mol}$. This contrasts 


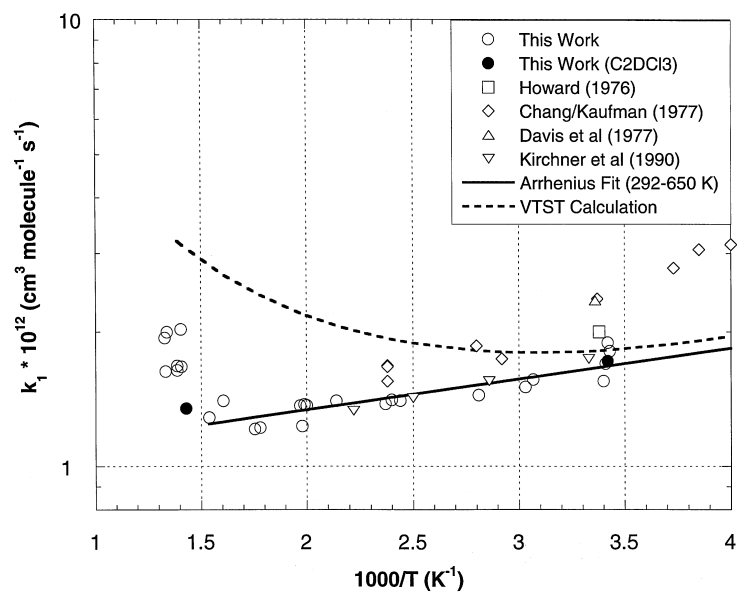

Fig. 1. Arrhenius plot of kinetic data for $k_{1}$. Also shown are the results of previous studies, an Arrhenius fit to the data from 291 to $650 \mathrm{~K}$, and the results of variational transition state theory calculations $(P=740 \pm 10$ Torr $)$.

with values of 2.4 and $2.0 \mathrm{kcal} / \mathrm{mol}$ reported by Chang and Kaufman (1977) and Kirchner, et al. (1990), respectively, over more limited temperature ranges. In this case, surface adsorption effects in the prior measurements, most prominent at lower temperatures, are inconsistent with the reduction in Arrhenius activation energy observed in our measurements. Previous studies have indicated that this reaction is not pressure dependent between 0.5 and 5.6 mbar (Kirchner et al., 1990). Theoretical calculations to be published elsewhere support the lack of a pressure dependence at these pressures (Tichenor et al., 1999). Therefore, the fact that the prior studies were performed at lower pressures (0.5-5.6 mbar) cannot explain the difference in reactivity. In the absence of reactant impurities, an explanation for the differences in reactivity for $k_{2}$ with increasing temperature currently elude us.

For $k_{1}$, rate coefficient measurements were also obtained with deuterated trichloroethylene to provide insight into the reaction mechanism. Rate coefficient measurements with $\mathrm{C}_{2} \mathrm{DCl}_{3}$ at 292 and $699 \mathrm{~K}$ indicate the absence of a measurable isotope effect (see Table 1). This result indicates that an $\mathrm{OH}$ addition mechanism dominates the measured $\mathrm{OH}$ decay rates throughout the temperature range of investigation. For $k_{2}$, an $\mathrm{OH}$ addition mechanism is also likely due to the large activation energy required for the $\mathrm{Cl}$ atom abstraction reaction $\left(\Delta H_{r \times n, 298}=28.7 \mathrm{kcal} / \mathrm{mol}\right){ }^{1}$

\footnotetext{
${ }^{1}$ Geometries, frequencies, and ZPE calculated using B3LYP/6-31G(d). Total energy calculated using B3LYP/6$311+\mathrm{G}(3 \mathrm{df}, 2 \mathrm{p})$.
}

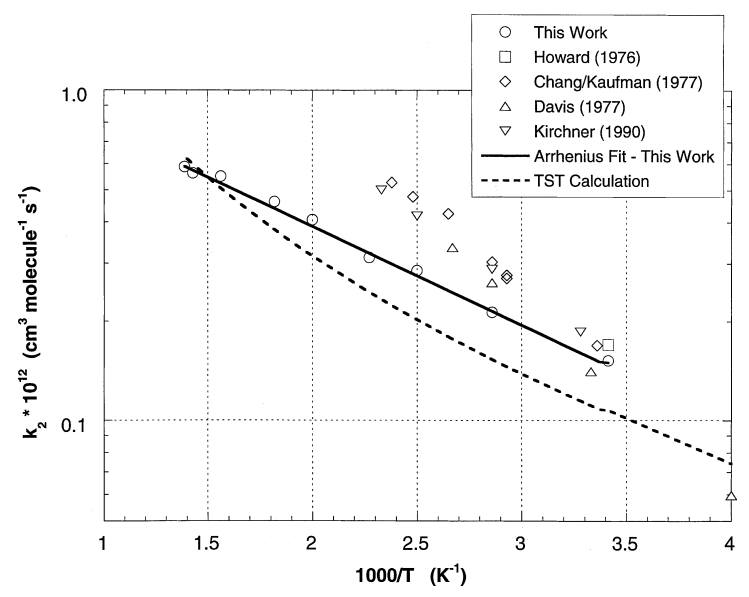

Fig. 2. Arrhenius plot of kinetic data for $k_{2}$. Also shown are the results of previous studies, an Arrhenius fit to the data, and the results of transition state theory calculations $(P=740 \pm$ 10 Torr).

\subsection{Theoretical calculations}

In addition to measured reaction rate expressions for $k_{1}$ and $k_{2}$, the reaction pathways and kinetics were analyzed using thermodynamic properties. Thermodynamic properties and kinetic parameters were determined for reactants, intermediate radicals, transition states (TSs), and products.

The potential energy diagram for $k_{1}$ is shown in Fig. 3(a) and (b) for $\mathrm{OH}$ radical attack at the $\alpha(\mathrm{CHCl})$ and $\beta\left(\mathrm{CCl}_{2}\right)$ site of the substrate. Literature values were used to estimate the $\Delta H_{f 298}^{\circ}$ of reactants (Stull and Prophet, 1971, Stull et al., 1987). GA method with THERM computer program (Ritter and Bozzelli, 1991) was used to calculate $\Delta H_{f 298}^{\circ}$ of intermediate radicals and products. Semi-empirical molecular orbital (MO) theory, PM3, with MOPAC6.0 computer code (Stewart, 1989), was performed to estimate $E_{\mathrm{a}}$ s except entrance channel. $E_{\mathrm{a}} \mathrm{s}$ were estimated by taking energy difference between reactants (intermediate radicals) and TSs obtained by PM3 theory. $\Delta H_{f}^{\circ} 298$ derived by PM3 contains systematical errors, however, they effectively cancel when $E_{\mathrm{a}} \mathrm{s}$ are calculated by difference.

The potential energy diagram for $k_{2}$ is shown in Fig. 4. The energies were evaluated using a composite $a b$ initio calculation, G3(MP2) (Curtiss et al., 1999) theory. Gaussian 94 and 98 computer codes were used to perform ab initio calculation on SGI-Origin2000 and Cray T-90 and 94 computers. The activation energy of TS0 (the entrance channel) was estimated using the higherlevel G3 calculation (Curtiss et al., 1998) since this channel determines the $\mathrm{OH}$ decay rate and is the most critical of the reaction mechanisms. Energy calculations were estimated using the reactants as the basis for the 


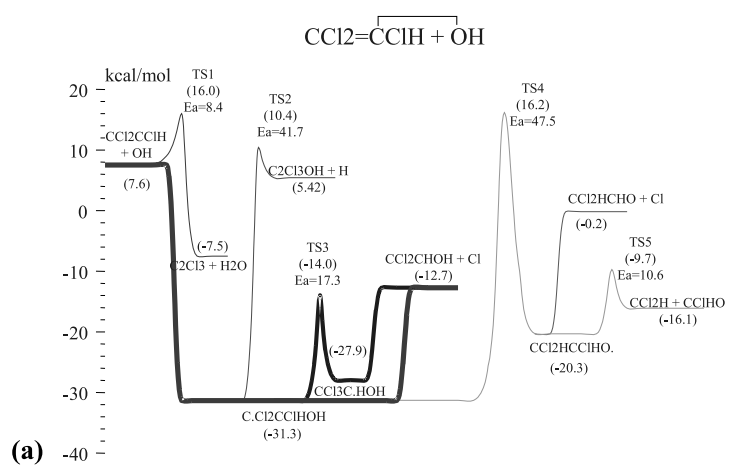

(a) -40

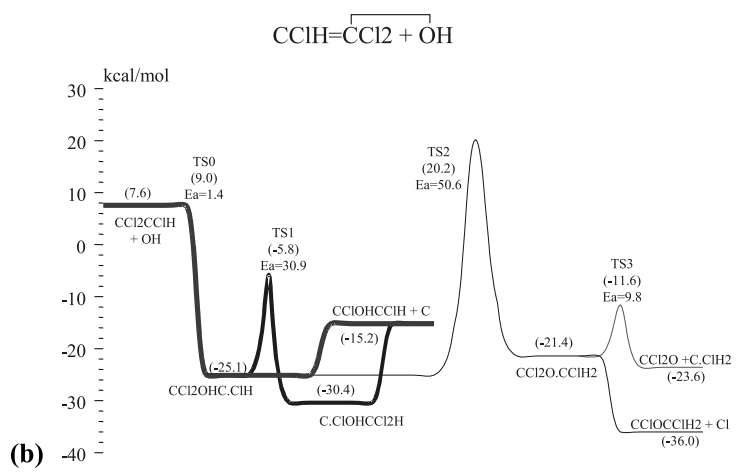

Fig. 3. (a) potential energy diagrams for the $\mathrm{OH}$ addition to $\mathrm{C}_{2} \mathrm{HCl}_{3}$ ( $\alpha$-site). Adduct stabilization, isomerization, $\mathrm{H}$ - and $\mathrm{Cl}$ atom elimination channels are shown. Energies were evaluated using GA for the intermediate radicals and products and PM3 for $E_{\text {a }}$ estimation. Thick lines represent energetically favorable pathways. (b) potential energy diagrams for the $\mathrm{OH}$ addition to $\mathrm{C}_{2} \mathrm{HCl}_{3}$ ( $\beta$-site). Adduct stabilization, isomerization, $\mathrm{H}$ - and $\mathrm{Cl}$ atom elimination channels are shown. Energies were evaluated using GA for the intermediate radicals and products and PM3 for $E_{\mathrm{a}}$ estimation. Thick lines represent energetically favorable pathways.

relative total energy difference. Zero point vibrational energy and thermal correction to $298 \mathrm{~K}$ were taken into account for the total energy calculation. Both G3 and G3(MP2) methods use HF/6-31G(d) level of theory to calculate frequencies and MP2(full)/6-31G(d) level of theory to optimize the geometry. G3 method then uses total energy calculated by QCISD(T)/6-31G(d), MP4/631G(d), MP4/6-31+G(d), MP4/6-31G(2df,p), and MP2(full)/G3large for the higher energy correction (Curtiss et al., 1998). G3(MP2) uses QCISD(T)/6$31 \mathrm{G}(\mathrm{d})$ and MP2(fc)/G3MP2large for the higher energy correction (Curtiss et al., 1999).

Variational transition state theory (VTST) calculations were performed to estimate the rate of $\mathrm{OH}$ addition to $\mathrm{C}_{2} \mathrm{HCl}_{3}$. In contrast to $\mathrm{C}_{2} \mathrm{Cl}_{4}$, conventional TST calculations are not useful because of the absence of a distinct barrier. The variational TST calculations were carried out as follows. First the reaction coordinate for

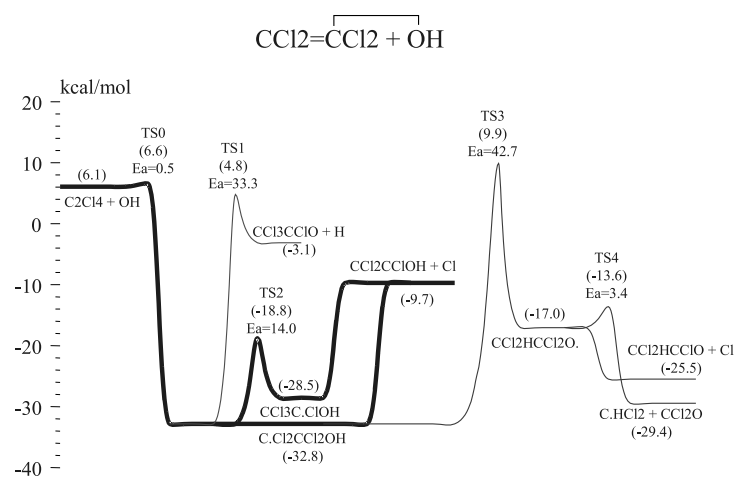

Fig. 4. Potential energy diagram for the $\mathrm{OH}$ addition to $\mathrm{C}_{2} \mathrm{Cl}_{4}$. Adduct stabilization, isomerization, $\mathrm{H}$ - and $\mathrm{Cl}$-atom elimination channels are shown. Energies were evaluated using G3(MP2) theory except for TS1 (MP2(full)/g-31G(d)), TS2 (B3LYP/6-31G(d)), and the intermediate isomer $\mathrm{CCl}_{2} \mathrm{HCCl}_{2} \mathrm{O} \bullet\left(\mathrm{MP} 2\right.$ (full)/g-31G(d)). $E_{\mathrm{a}}$ for TS1 was estimated by taking a difference between products and TS1 using MP2(full)/6-31G(d) level of theory because of convergence failure at the higher level of theory. $E_{\mathrm{a}}$ for TS2 was estimated using B3LYP/6-31G(d) level of theory because of optimization difficulty using MP2(full)/6-31G(d) level of theory and convergence failure at the higher level of theory. Thick lines represent energetically favorable pathways.

addition of $\mathrm{OH}$ to the $\mathrm{C}=\mathrm{C}$ bond was defined as a distinguished coordinate pathway (DCP) at the HF/6$31 \mathrm{G}(\mathrm{d}, \mathrm{p})$ level. The geometry of the system was optimized at various fixed $\mathrm{C}-\mathrm{O}$ separations, and frequencies were obtained normal to the DCP also at the HF/6$31 \mathrm{G}(\mathrm{d}, \mathrm{p})$ level of theory. Then energies were computed at the spin-projected PMP4/6-311+G(d,p) level, relative to reactants. These energies, geometries, and frequencies were used to derive conventional TST rate constants as a function of position along the DCP. At each temperature, the VTST result was obtained by interpolation to find the minimum rate constant.

\section{Discussion}

The complex temperature dependence of $k_{1}$ is qualitatively consistent with VTST calculations of the entrance channel for the addition of $\mathrm{OH}$ to the $\mathrm{H}$ substituted side of the double bond of the substrate, which is based on PMP4/6-311+G(d,p) energies, the dominant site for addition (Kirchner et al., 1990). As illustrated in Fig. 1, these calculations exhibit a negative temperature dependence at low temperatures $(<300 \mathrm{~K})$ followed by a transition to a positive temperature dependence above $\sim 500 \mathrm{~K}$. The calculated transition state for the entrance channel is below the total energy of the reactants and is responsible for the negative temperature dependence at low temperatures. The transition to a positive 
temperature dependence at higher temperatures is due to the increasing importance of the partition function that characterizes the transition state relative to the reactants. VTST calculations indicate that $\mathrm{OH}$ addition to the $\alpha$ site is the dominant reaction under the experimental conditions (Marshall et al., 2000). $\mathrm{OH}$ addition to the $\beta$ site has a positive energy barrier and a factor of 8 lower A factor. This reaction increases in importance at very high temperatures $(>2000 \mathrm{~K})$. The lack of a measurable kinetic isotope effect is consistent with this analysis.

The positive temperature dependence of $k_{2}$ is consistent with the location of a transition state for $\mathrm{OH}$ addition to the $\pi$ electron system that lies higher in energy than that of the reactants. This is in contrast to $k_{1}$ where the energy of the transition state (for $\mathrm{OH}$ addition to the $\alpha$ site) was below the energy of the reactants. Comparison of the measured rate coefficients with conventional TST calculations for the $\mathrm{OH}$ addition channel indicate generally good agreement, particularly at higher temperatures (see Fig. 2). The atypical large barrier for $\mathrm{OH}$ addition explains the metathesis-like behavior of the Arrhenius plot.

The potential energy surfaces shown in Figs. 3 and 4 provide some insight into the potential reaction mechanisms for $k_{1}$ and $k_{2}$, respectively. These surfaces indicate that both reactions are very likely chemically activated. Low energy $\mathrm{Cl}$ elimination pathways are available in both systems. The $\mathrm{Cl}$ elimination pathway is particularly facile for $k_{2}$, and may be expected to dominate from room temperature to temperatures characteristic of combustion systems. A $\mathrm{H}$ elimination channel may also contribute to the overall reaction at very high temperatures, in excess of $2000 \mathrm{~K}$. The $\mathrm{Cl}$ elimination pathway is also favorable for $k_{1}$, but adduct stabilization is expected to be important at low temperatures due to the lack of an appreciable barrier to the formation of the activated complex. The lack of an experimentally observable $\mathrm{H}$ atom abstraction channel is consistent with the potential energy calculations for $k_{1}$ that indicate a substantial activation energy for this reaction.

Quantum RRK calculations based on the input parameters described in this manuscript are in progress and will be published in subsequent papers dealing with the kinetics and mechanism of reaction of $\mathrm{OH}$ with $\mathrm{C}_{2} \mathrm{HCl}_{3}$ and $\mathrm{C}_{2} \mathrm{Cl}_{4}$.

\section{Conclusions}

Rate coefficients are reported for the gas-phase reaction of the hydroxyl radical $(\mathrm{OH})$ with $\mathrm{C}_{2} \mathrm{HCl}_{3}\left(k_{1}\right)$ and $\mathrm{C}_{2} \mathrm{Cl}_{4}\left(k_{2}\right)$ over an extended temperature range at $740 \pm 10$ Torr in a He bath gas. The room temperature values for $k_{1}$ and $k_{2}$ are within $\pm 2 \sigma$ of previous data using different techniques. The temperature-dependent behavior of $k_{1}$ was observed to be complex, with the reaction exhibiting a slight negative activation energy below $650 \mathrm{~K}$ and a slight positive activation energy at higher temperatures $(650-750 \mathrm{~K})$. This contrasts with a factor of roughly 2-3 larger negative activation energy observed in previous lower temperature studies. The positive activation energy observed for $k_{2}(293-720 \mathrm{~K})$ is about a factor of two lower than observed in previous lower temperature measurements. On the basis of potential energy surface calculations, reaction mechanisms involving $\mathrm{Cl}$ elimination are proposed to be important pathways in the oxidation of these compounds. $\mathrm{H}$ atom abstraction was not observed to be significant for $k_{1}$ under our experimental conditions, i.e., atmospheric pressure.

\section{Acknowledgements}

The authors acknowledge support from the Environmental Protection Agency (Grant R82-6169-01-0). The authors would also like to thank Dr. J.W. Bozzelli for his comments during the ab initio calculations. While this research has been supported by the US-EPA, it has not been subject to Agency review and therefore does not necessarily reflect the views of the Agency, and no official endorsement should be inferred.

\section{References}

Atkinson, R., 1989. J. Phys. Chem. Ref. Data, Monogr. 1.

Atkinson, R., Aschmann, S.M., Goodman, M.A., 1987. Int. J. Chem. Kinet. 19, 299.

Chang, J.S., Kaufman, F.J., 1977. Chem. Phys. 66, 4989.

Cox, R.A., 1974. J. Photochem. 3, 175.

Curtiss, L.A., Raghavachari, K., Redfern, P.C., Rassolov, V., Pople, J.A., 1998. J. Chem. Phys. 109, 7764.

Curtiss, L.A., Redfern, P.C., Raghavachari, K., Rassolov, V., Pople, J.A., 1999. J. Chem. Phys. 110, 4703.

Davis, D., Machado, U., Smith, G., Wagner, S., Watson, R.T., 1977. In: Watson, R.T., (Ed.), J. Phys. Chem. Ref. Data 6, p. 871, unpublished.

Demore, W.B., Goldent, D.M., Hampson, R.F., Kurylo, M.J., Howard, C.J., Ravishankara, A.R., Kolb, C.E., Molina, M.J. Jet Propulsion Laboratory Publ. 97-4, Chemical Kinetics and Photochemical Data for Use in Stratospheric Modeling, \#12, National Aeronautics and Space Administration, 1997.

Fairchild, P.W., Smith, G.P., Crosley, D.R., 1982. In: Proceedings of the Nineteenth International Symposium on Combustion, The Combustion Institute, p. 107.

Fang, T.D., Taylor, P.H., Berry, R.J., 1999. J. Phys. Chem. A 103, 2700.

Fang, T.D., Taylor, P.H., Dellinger, B., Ehlers, C.J., Berry, R.J., 1997. J. Phys. Chem. 101, 5758. 
Gilbert, D., Goyer, M., Lyman, W., Magil, G., Walker, P., Wallace, A., Wechsler, A., Yee, J. An exposure and risk assessment for tetrachloroethylene, EPA-440/4-85-015, 1980.

Howard, C.J., 1976. J. Chem. Phys. 65, 4771.

Kirchner, K., Helf, D., Ott, P., Vogt, S., 1990. Ber. Bunsenges. Phys. Chem. 94, 77.

Mallard, W.G., 1998. NIST Chemical kinetics database 2Q98, NIST standard reference database 17, US Department of Commerce, Gaithersburg, MD.

Marshall, P., Peng, J., Hu, X, El-Sinawi, A., Yamada, T., Taylor, P.H., In: proceeding 16th Int'l Symp. on Gas Kinetics, Cambridge, UK, July 2000.

Ritter, E.R., Bozzelli, J.W., 1991. J. Chem. Info. Comput. Sci. $31,400$.

Stewart, J.J.P., 1989. J. Comput. Chem. 10, 209.
Stull, D.R., Prophet, H., 1971. JANAF thermochemical tables second ed., US Department of Commerce, Gaithersburg, MD.

Stull, D.R., Westrum, J.E.F., Sinke, G., 1987. The Chemical Thermodynamics of Organic Compounds. Wiley, New York.

Thomas, R., Byrne, M., Gilbert, D., Goyer, M., Moss, K., 1981. An exposure and risk assessment for trichloroethylene, EPA-440/4-85-019.

Tichenor, L.B., Taylor, P.H., Yamada, T., Peng, J., Hu, X., Marshall, P., 1999. J. Phys. Chem. A, submitted.

Warnatz, J., Bockhorn, H., Moser, A., Wenz, H.W., 1982. In: Proceedings of the Nineteenth International Symposium on Combustion, The Combustion Institute, p. 197.

Zabel, F., 1974. Ber. Bunsenges. Phys. Chem. 78, 232. 